\title{
ЭЛЕКТИВНЫЙ КУРС «ПОСТОЯННЫЙ ТОК» С ПРИМЕНЕНИЕМ МАКЕТНОЙ ПЛАТЫ СТАНЦИИ NI ELVIS II
}

\section{ELECTIVE COURSE «DIRECT CURRENT» WITH THE USE OF THE BREADBOARD OF THE STATION NI ELVIS II}

\section{R. Petrova \\ O. Litvintseva}

Summary: The INT-EE breadboard of the National Instruments ELVIS II workstation is widely used in higher educational institutions for laboratory work. This article examines the possibility of using a workstation in the educational process in a secondary school as part of an elective course. Has been complied a general logical framework of activities and the instructions specially adapted for students to perform laboratory work on the subject of «Direct Current». Generalized methods of activity allowed students of a profile class to successfully use virtual measuring instruments and components of a computer system collecting measurement data when performing laboratory work on a student level.

Keywords: elective course, generalized methods of activity, laboratory work in physics, NI ELVIS II workstation, virtual measuring instruments.
Петрова Раиса Иннокентьевна

К.т.н., дочент, ФГАОУ ВО «Северо-Восточный федеральный университет им М.К. Аммосова» (Якутск) rain72@mail.ru

Литвинцева Ольга Алексеевна ФГАОУ ВО «Северо-Восточный федеральный университет им М.К. Аммосова» (Якутск) litvincevaolya@gmail.ru

Аннотация: Макетная плата INT-EE рабочей станции National Instruments ELVIS II широко применяется в высших учебных заведениях для проведения лабораторных работ. В статье исследуется возможность использования рабочей станции в учебном процессе в средней образовательной школе в рамках элективного курса. Составлены общая логическая схема деятельности и адаптированные для учащихся инструкции по выполнению лабораторных работ по теме «Постоянный ток». 0бобщенные приемы деятельности позволили учащимся профильного класса успешно на уровне студентов использовать виртуальные измерительные приборы и компоненты системы сбора компьютером данных измерений.

Ключевые слова: элективный курс, обобщенные приемы деятельности, лабораторные работы по физике, рабочая станция NI ELVIS II, виртуальные измерительные приборы.

Чтобы заинтересовать современного ученика, на наш взгляд, нужно ему предложить современные средства эксперимента с использованием технологии виртуальных приборов. Одним из таких средств является программно-аппаратное обеспечение National Instruments в виде учебной станции NI ELVIS II+, работающей со специально разработанной макетной платой для проведения лабораторных работ.

В школьной программе по физике с каждым годом все меньше часов на лабораторные работы, тем более на практике в школе почти не используют программно-аппаратные средства National Instruments. В связи с этим, нами были выбраны внеучебные занятия, в частности элективные курсы, где учащиеся могли бы получить необходимый опыт в измерениях различных физических величин, используя платформу NI ELVIS. Таким образом, объектом исследования является учебный процесс в элективном курсе в профильном классе общеобразовательной школы. Предмет исследования - методика проведения лабораторных работ по теме «Постоянный ток», используя рабочую станцию National Instruments ELVIS II. Цель исследования: разработка методики проведения лабораторных работ на макетной плате INT-EE рабочей станции NI ELVIS II в рамках элективного курса. 


\section{Материал и методы исследования}

Лабораторно-техническая платформа NI ELVIS II+, разработанная специально для учебных заведений, широко применяется в вузах технического профиля [3]. Аппаратная часть комплекса включает в себя настольную учебную станцию «NI ELVIS II +» со специальной макетной платой INT-EE сбора данных для проведения лабораторных работ, источник питания, USB кабель для связи с компьютером, персональный компьютер с установленным программным обеспечением NI ELVIS. Оборудование имеет большое количество встроенных виртуальных приборов для лабораторных работ, разработанных в программной среде LabVIEW. Программное обеспечение NI ELVIS служит для управления функционированием аппаратных средств NI ELVIS II с помощью спроектированных в LabVIEW лицевых панелей (Soft Front Panels - SFPs) [4].

Из всех лабораторных практикумов для технических вузов [4] нами выбран практикум по основным разделам теоретических основ электротехники, который наиболее подходит для учащихся технического профиля. Из практикума выбраны лабораторные работы по теме «Постоянный ток»: «Закон Ома», «Законы Кирхгофа», «Последовательное соединение резисторов», «Параллельное соединение резисторов», «Смешанные соединения резисторов». Из этих работ лабораторные работы «Законы Кирхгофа» и «Смешанные соединения резисторов» традиционно в средних образовательных школах не проводятся. Для учащихся были адаптированы инструкции по выполнению лабораторных работ.

При деятельностном подходе в обучении выделяют действия, которые являются общими для частных видов деятельности, их называют обобщенными приемами [2]. Обучение учащихся обобщенным приемам занимает значительно меньше времени, чем обучение решению конкретных задач, так как спектр таких задач обширный. В данной работе к обобщенным приемам относятся разработанные нами общая логическая схема деятельности (ОЛС) по выполнению лабораторных работ и общая система действий по составлению отчета. Разработанная ОЛС содержит действия, помогающие ученику выбирать из меню лабораторную работу, работать с интерактивным представлением схем в каждой работе, собирать цепь на макетной плате, измерять физические величины виртуальными приборами, делать экспорт данных в формат MS Excel и представлять экспериментальные результаты в виде таблиц, графиков, осциллограмм и векторных диаграмм. Общая система действий по составлению отчета состоит из 13 действий, подходит для всех пяти работ и является весьма удобной при сравнении работ обучающихся разных групп.

\section{Результаты исследования и их обсулкение}

Элективный курс проводился среди учеников 11 класса физико-математического профиля ГБНОУ Республиканского интерната-лицея г. Якутска в 2018-2019 и 2019-2020 учебных годах, всего охвачено 22 учащихся. Элективный курс состоит из 16 часов, из них в течение 5 часов учащиеся изучали функциональные возможности макетной платы и обобщенные приемы, а в остальные часы выполняли 5 лабораторных работ. В элективном курсе учащиеся познакомились с современным подходом к выполнению лабораторного практикума, заключающегося в применении виртуальных измерительных приборов и компонентов системы сбора данных измерений. Учащиеся убедились, что компьютер можно применять как измерительную станцию, которая может накапливать результаты измерений, сохранять их, производить математические операции над результатами измерений, помогать формировать отчеты. Учащиеся научились составлять отчет, опираясь на систему действий по его оформлению.

Коэффициент успешности выполнения лабораторной работы $K$ вычислили, используя методику, предложенную авторами [5]: $K=\frac{\sum N_{i}}{N * n}$, где $N_{i}$ - число правильно выполненных действий отчета по выполнению лабораторной работы $i$ - тым учащимся; $N$ - общее число действий отчета по выполнению данной работы; $n$ - число учащихся. Значения коэффициентов успешности выполнения каждого действия по выполнению лабораторной работы $\left(K_{1}, K_{2}, K_{3} \ldots K_{13}\right)$ приведены в таблице 1.

Из таблицы 1 видно, что действия: $K_{9}$ - анализ данных

Коэффициенты успешности выполнения К учащимися каждого действия по выполнению лабораторных работ

\begin{tabular}{|l|c|c|c|c|c|c|c|c|c|c|c|c|c|}
\hline K & $K_{1}$ & $K_{2}$ & $K_{3}$ & $K_{4}$ & $K_{5}$ & $K_{6}$ & $K_{7}$ & $K_{8}$ & $K_{9}$ & $K_{10}$ & $K_{11}$ & $K_{12}$ & $K_{13}$ \\
\hline Закон Ома & 1 & 1 & 1 & 1 & 1 & 1 & 0.9 & 1 & 0.7 & 0.5 & 0.7 & 0.9 & 1 \\
\hline Закон Кирхгофа & 0.9 & 1 & 1 & 0.8 & 1 & 0.8 & 0.9 & - & 0.8 & 0.7 & 0.7 & 1 & 0.7 \\
\hline Последовательное соединение & 0.8 & 1 & 1 & 1 & 0.6 & 1 & 0.8 & 0.8 & 0.7 & - & - & 1 & 1 \\
\hline Параллельное соединение & 0.8 & 1 & 1 & 0.9 & 0.8 & 0.9 & 0.9 & 0.8 & 0.4 & - & - & 1 & 0.9 \\
\hline Смешанное соединение & 0.9 & 1 & 1 & 0.8 & 0.7 & 1 & 0.9 & 0.9 & 0.7 & - & - & 1 & 0.9 \\
\hline
\end{tabular}


Коэффициенты успешности выполнения К (общий) лабораторных работ учащимися и студентами

Таблица 2.

\begin{tabular}{|l|l|l|l|l|l|} 
& Закон Ома & Закон Кирхгофа & $\begin{array}{l}\text { Последователь- } \\
\text { ное соединение }\end{array}$ & $\begin{array}{l}\text { Параллельное } \\
\text { соединение }\end{array}$ & $\begin{array}{l}\text { Смешанное } \\
\text { соединение }\end{array}$ \\
\hline Учащиеся & 0.89 & 0.86 & 0.86 & 0.90 & 0.90 \\
\hline Студенты & 0.74 & 0.80 & - & - & 0.99 \\
\hline
\end{tabular}

измерений, $K_{10}$ - построение графика зависимости одной величины от другой, $K_{11}$ - анализ графика вызвали некоторые затруднения у учащихся. Ответы на контрольные вопросы $\left(K_{13}\right)$ показали, что теоретические материалы усвоены на высоком уровне.

Для выявления эффективности разработанной методики выполнения лабораторных работ результаты учащихся сравнили с результатами лабораторных работ, выполненных студентами-бакалаврами 4 курса Физикотехнического института (16 человек) в рамках спецкурса «Электротехника». Студенты выполнили лабораторные работы «Закон Ома», «Закон Кирхгофа» и «Смешанное соединение резисторов», используя «Руководство пользователя». Отчет лабораторных работ сделали по общей схеме по оформлению отчетов. Результаты сравнения отчетов учащихся 11 класса и студентов 4 курса приведены в таблице 2 .

Из таблицы 2 видно, что общие коэффициенты успешности выполнения 5 лабораторных работ по теме «По- стоянный ток» у учащихся колеблется от 0.86 до 1.00 (в процентах 86-100), а у студентов при выполнении работ «Закон Ома», «Закон Кирхгофа» и «Смешанное соединение резисторов» колеблется от 74\% до 99\%.

Сравнение результатов выполнения учащимися и студентами 4 курса, готовящимися стать учителями физики, показало, что учащиеся не отстают от студентов, что показывает эффективность методики, основанной на применении общих логических схем деятельности по выполнению лабораторных работ.

Таким образом, элективный курс показал возможность использования макетной платы INT-EE рабочей станции NI ELVIS II в учебном процессе в средних образовательных школах. Учащиеся успешно на уровне студентов использовали виртуальные измерительные приборы и компоненты системы сбора данных, опираясь на общую логическую схему деятельности и на адаптированную инструкцию выполнения лабораторных работ.

\section{ЛИТЕРАТУРА}

1. Анофрикова С.В. Как найти выход из кризиса образования // Физика. Первое сентября. 2011. №12, С. 6-7.

2. Анофрикова С.В. Азбука учительской деятельности, иллюстрированная примерами деятельности учителя физики Ч.1. Разработка уроков. [Изд. 2-е, перераб и доп.]. М.: МПГУ, 2007. 325 с.

3. Ю.Н. Дьяченко. Применение комплекта оборудования NI ELVIS II фирмы National Instruments Corporation в лабораторном практикуме: учебное пособие [Электронный ресурc] URL: https://elib.spbstu.ru/dl/2368.pdf/view (дата обращения 20.06.2020).

4. Лаборатория по теоретическим основам электротехники. [Электронный ресурс]. URL: https://adv-techno.ru/physics/teoretich_osnovam_electrotehniki_1/ (дата обращения 20.06.2020).

5. Калугина Н.Л., Гиревая Х.Я., Калугин Ю.А., Варламова И.А. Критерии сформированности исследовательских умений студентов технических вузов // Успехи современного естествознания. 2015. №7. С. 98-101.

() Петрова Раиса Иннокентьевна (rain72@mail.ru), Литвинцева Ольга Алексеевна (litvincevaolya@gmail.ru). Журнал «Современная наука: актуальные проблемы теории и практики» 